\title{
Clinical observations and experiments in diabetic neuropathy*
}

\author{
P.J.Watkins \\ Diabetic Department, King's College Hospital, London, UK
}

\begin{abstract}
Summary. Diabetic neuropathies form a group of diverse conditions, which can be distinguished between those which recover (acute painful neuropathies, radiculopathies, mononeuropathies) and those which progress (sensory and autonomic neuropathies). These two main groups can be distinguished in several ways: sensory and autonomic neuropathies are classic diabetic complications progressing gradually in patients with long-standing diabetes who often have other specific complications, while the reversible neuropathies do not have these features. The latter are characterised by their occurrence at any stage of diabetes, often at diagnosis, they may be precipitated on starting insulin treatment, and they are more common in men; they can occur at any age,
\end{abstract}

though more often in older patients, and are unrelated to other diabetic complications. The two groups of neuropathies also show differences in nerve structural abnormalities and with regard to distinctive blood flow responses. The underlying mechanisms responsible for these very different forms of neuropathy remain speculative, but evidence for an immunological basis for the development of severe symptomatic autonomic neuropathy is presented.

Key words: Diabetic neuropathy, autonomic neuropathy, painful neuropathy, mononeuropathy, blood flow, nerve biopsies.
Nerve damage is common in diabetes mellitus and has been recognised for nearly two centuries. It takes several different forms resulting in diverse clinical problems thus strongly suggesting that no single mechanism can be responsible.

This review has two themes: the first examines the distinctions between neuropathies which recover and those which progress; the second is the encouragement of clinical research and observations which should be the precursors of experimental research, well expressed by the physician J.A. Ryle in his essay "The Physician as Naturalist" [1]: "..... nearly all experiments have developed on the basis of earlier painstaking observations of natural phenomena".

The natural history of the different neuropathies is described, with observations on physiological and structural differences which may distinguish those which recover from those which progress, together with some suggestions regarding immunological mechanisms.

\footnotetext{
* This review was presented as the Camillo Golgi lecture at the EASD meeting in Copenhagen, September 1990
}

\section{General observations}

Peripheral nerves are prone to several different types of insult in diabetes, so that nerve function can deteriorate in response to pressure, ischaemia or metabolic abnormalities, possibly exacerbated by alcohol. Pressure palsies, notably carpal tunnel syndrome, and almost certainly ulnar nerve damage and foot drop are more common in diabetic patients than non-diabetic subjects and are not discussed further in this review.

Some neuropathies in diabetes have a relatively acute onset, follow a defined course, and recover after several months, usually completely. Mononeuropathies, especially proximal motor or femoral neuropathy (otherwise known as amyotrophy) and ocular palsies, radiculopathies (especially affecting the trunk) and acute painful neuropathies are included in this category. They are unrelated to the duration of diabetes or to the other long-term complications and are more common in men with Type 2 (non-insulin-dependent) diabetes. Diabetes may present with these symptoms, and they may present several weeks after starting insulin treatment. Their pathology and the basis for their recovery is obscure, although nerve microinfarcts have been reported in 
Table 1. Painful neuropathies and mononeuropathies

\begin{tabular}{lllll}
\hline & $\begin{array}{l}\text { Painful } \\
\text { neuropathy } \\
{[11]}\end{array}$ & $\begin{array}{l}\text { Truncal } \\
\text { radiculo- } \\
\text { pathy [21] }\end{array}$ & $\begin{array}{l}\text { Femoral } \\
\text { neuropathy } \\
{[25]}\end{array}$ & $\begin{array}{l}\text { Ocular } \\
\text { palsies } \\
{[26]}\end{array}$ \\
\hline $\begin{array}{l}\text { Male : female } \\
\begin{array}{l}\text { Duration } \\
\text { (months) }\end{array}\end{array}$ & all male & all male & $2.4: 1$ & $3.3: 1$ \\
$\begin{array}{l}\text { Review } \\
\text { (years) }\end{array}$ & $4-6$ & $4-30$ & $3-12$ & $<6$ \\
\hline
\end{tabular}

individual ocular palsies and proximal motor neuropathies.

Sensory neuropathy which is often associated with autonomic neuropathy is a diffuse and symmetrical disorder. It is a more conventional diabetic complication in that it occurs as a result of long-term diabetes and is often associated with other complications. It progresses with the duration of diabetes, but the rate of progression is quite variable, though usually slow, over several decades: it never recovers. The contrast with the neuropathies which recover is very striking.

There have been several recent reviews of diabetic neuropathies [2-9].

\section{Natural history of diabetic neuropathies}

Sir James Mackenzie once said: " . . . it is the family doctor who alone saw disease in its true perspective as he had the advantage of observing early symptoms and following an illness from beginning to end [10]".

In the present context "the family doctor" can be replaced by "the diabetic physician", who is uniquely placed to make long-term observations on his patients. I will review studies which observe the courses of the different neuropathies up to 15 years. Such observations are scarce in the literature on this subject.

\section{Neuropathies which recover: acute painful neuropathies, radiculopathies, mononeuropathies and ocular palsies} (Table 1)

\section{Acute painful neuropathies [11-15]}

Acute and disabling continuous pain sometimes affects diabetic patients: it occurs either in a stocking distribution affecting the feet and legs (I have only rarely seen it affecting the hands), in the thighs in cases of femoral neuropathy, or it may involve the trunk in cases of radiculopathy. It is very different from the relatively mild paraesthesiae which so commonly affects the toes of diabetic patients for an indefinite period and so often in the literature is described as "pain".

Diagnosis of painful neuropathy demands careful attention to the description of symptoms because correlation with physically demonstrable neuropathy is poor: while some patients have major defects of neuropathy with numb feet which are also painful ("the painless painful foot" described by J.D. Ward [16]), others have scarcely any features of neuropathy with intact reflexes, normal autonomic function and near normal electrophysiology. The cause of the pain is much discussed but quite obscure. The pain in this condition can be exceptionally distressing. It is protracted and unremitting, lasting many months. Constant burning sensations which have been likened to walking on burning sand, together with paraesthesiae and shooting or searing pains are often described. There is a subjective sensation of swollen feet. Exquisite contact discomfort is characteristic, such that patients cannot bear the soreness caused by clothes and bed-clothes and therefore go to great lengths to avoid such contact: some men remove their trousers at the earliest opportunity, some wear very soft, sometimes silk, underwear, and I know one patient who was unable to share his bed with his wife because even the lightest contact was so painful. Relief is sometimes obtained by cooling the feet by exposing them out of the bed-clothes, or in bowls of cold water, cold showers or even paddling in the sea. Symptoms are worse at night causing insomnia and depression. Severe weight loss is the rule in this condition and this combination of weight loss with pain often leads to a fruitless search for malignancy.

Painful neuropathy can occur at any age or stage of diabetes and may be its presenting symptom. As with mononeuropathies and radiculopathies, it is unrelated to other complications of the disease and it is more common in men. The commencement of insulin treatment often precedes the onset of symmetrical painful neuropathy by a few weeks. This sequence of events is reported in several of the descriptions of this disorder though the scientific basis for the observation is not understood: it bears an uncomfortable analogy to the acceleration of retinopathy which occasionally occurs when diabetes control is severely tightened as in the case of continuous subcutaneous insulin infusion and this has also been described in a case of painful neuropathy [15].

Weight loss in cases of painful neuropathy is profound (Fig. 1): in nine cases of symmetrical distal painful neuropathy we have described, the mean weight loss was $14 \mathrm{~kg}$ (range $10-27 \mathrm{~kg}$ ) representing on average a $19 \%$ loss of body weight (range 12-35\%) [11]. This led Ellenberg to describe the syndrome as "diabetic cachexia" [14]. It is interesting that the weight loss may precede the development of pain.

Steel et al. in Edinburgh have also drawn attention to a high prevalence of eating disorders amongst young Type 1 (insulin-dependent) diabetic patients and described painful neuropathy in 4 or 15 cases where there had been severe weight loss in association with anorexia nervosa [17]. Recovery from pain is always accompanied by restitution of normal body weight: we have the impression that the increase in weight preceded the recovery from pain. One recent study suggested the possibility of malabsorption in these patients. The idea therefore that a nutritional deficit may be of importance is of interest and the similarity of pain in cases of beri-beri is said to be very striking. Vitamin treatment is, however, without effect in diabetic neuropathy. 

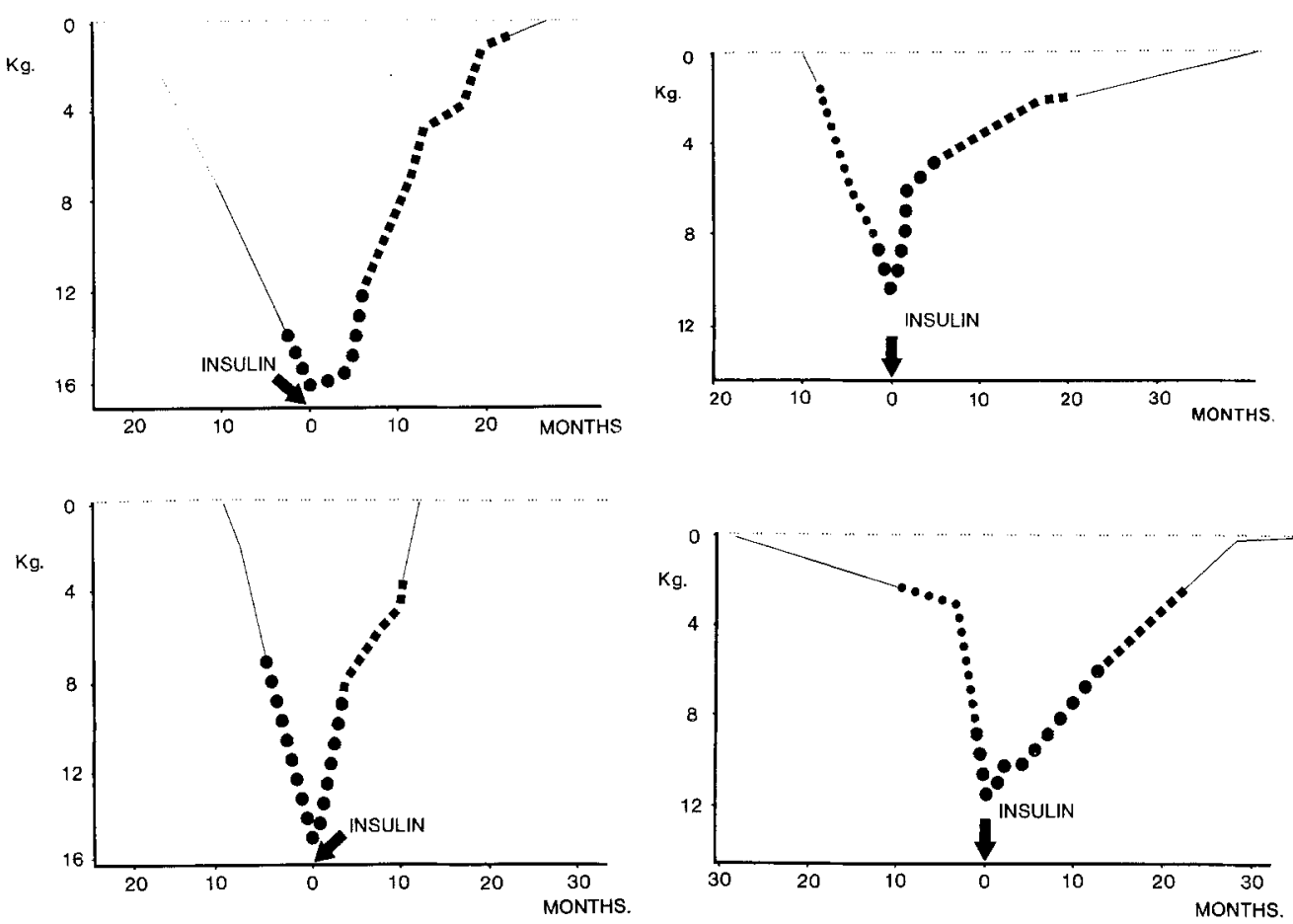

Fig. 1. Weight loss $(\mathrm{kg})$ in four patients with acute painful neuropathy [11]. The severity of the pain is denoted by the size of the circles $(\bullet)$ while the squares (ש) indicate residual symptoms. All four patients had baseline weights between 70 and $80 \mathrm{~kg}$, shown by the horizontal dashed line
Recovery from severe pain is usually complete in 10 months and patients may regain lost tendon reflexes: they do not necessarily progress to conventional sensory neuropathy though some obviously do. Symptoms in patients with lesser degrees of discomfort however often persist, sometimes for many years: in one study, 36 of 39 patients showed no change of symptoms up to 5 years [18]. Methods of achieving pain relief in these patients is reviewed elsewhere [2].

Attempts by Young et al. in Edinburgh to identify clinical differences between patients whose symptoms remitted and those in whom they did not, have been unsuccessful although remission was found to occur most often if the onset of the pain was related to rapid improvement of control and in those with the most severe weight loss [19]. They also demonstrated some improvement of both electrophysiological and autonomic function tests in the patients who recovered. Review of our patients up to 6 years showed no relapse [11].

\section{Radiculopathies}

Any nerve root can be involved [20] although the trunk is more commonly affected, usually over the abdominal wall, i.e. lower thoracic and upper lumbar nerve roots. The condition is often unilateral, with involvement of several adjacent nerve roots; a recent review of seven patients, all men, found that half of them had bilateral involvement [21]. During a review period of two and a half years, the seven patients experienced 17 episodes of pain which resolved between 4 months and two and a half years. Motor involvement is rare, but weakness of the abdominal wall can lead to striking abdominal bulges, which resolve completely as recovery occurs [22].
The pain characteristics are exactly the same as those described above. I have seen one patient who developed truncal radiculopathy 5 years after femoral neuropathy who noted that the pain and contact sensitivity were identical. Contact discomfort is a prominent symptom and it is often possible to delineate the affected area exactly and reproduce it simply by tracing it with a finger. When the pain affects the abdominal wall, as it often does, its cause is frequently unrecognised and quite extensive abdominal investigations undertaken before the correct diagnosis is made. It is always important to exclude other causes of nerve root compression before reaching definite conclusions.

\section{Mononeuropathies - Proximal motor neuropathy (femoral neuropathy: diabetic amyotrophy)}

Pain with or without wasting in one or sometimes both thighs are the cardinal features of this condition [23-25]. It develops over several weeks and may be very unpleasant both because of the pain (described above), or the thigh weakness and wasting which can be so severe that falls become inevitable and climbing stairs impossible. Upon examination the knee jerk is absent and the ankle jerk may be present. It is important to exclude other causes of nerve root compression before reaching a conclusive diagnosis.

Femoral neuropathy is more common in Type 2 diabetic men, on average in their sixties. It is unrelated to diabetes duration and not uncommonly its presenting symptom. It is often bilateral, the second side becoming involved either simultaneously with the first or within a few weeks. We have recently reviewed 27 such patients for up to 14 years [25]. Recovery is the rule with the worst pain resolving in 6 to 12 months and the remaining dis- 
comfort disappearing over about 3 years. The knee jerk returned in about half the cases over 4 years and function recovered completely even in the worst cases, although some slight measureable wasting may persist. Relapses after the first few weeks during which the contralateral side may be affected, are rare.

\section{Ocular palsies}

Cranial nerve palsies affecting almost equally the $3 \mathrm{rd}$ and 6th nerves are associated with diabetes [26]. Other associations, for example lesions of the 4 th and 7 th nerves are less well established. The onset of the nerve palsy is abrupt and patients with 3rd nerve lesions may complain of supraorbital pain; in these cases, there is usually pupillary sparing and an absence of ptosis. The condition is more common in men, resolves completely in 3-6 months, and in our review of 11 patients between 1 and 10 years there were only two relapses occurring after the first episode.

After reviewing the clinical features and course of disease in patients with acute painful neuropathies, radiculopathies, proximal motor neuropathies and ocular palsies one may draw several conclusions. These syndromes which are sometimes precipitated by the start of insulin treatment are more common in men of any age, though more frequent in later years. Both Type 1 and Type 2 diabetic patients are affected, the latter perhaps more commonly. There is no relationship with duration of diabetes and the symptoms may mark the presentation of the diabetes itself. There is, therefore, no relationship with other conventional diabetic complications. Recovery is the rule in these neuropathies and they do not normally relapse after the first few weeks during which contralateral symptoms may develop. The idea that microvascular disease might be responsible for these features seems improbable when viewed in the light of these clinical features. Joslin himself made these clinical observations many years ago:

"Mild cases respond in some weeks: severe and long-lasting neuropathies may take months or even a year to get relief from symptoms. It is common for treatment to increase pain for a time - but perseverance and the use of analgesics is always rewarded".

\section{Symmetrical somatic polyneuropathy and autonomic neuropathy}

These neuropathies are diffuse and symmetrical and usually associated with each other, although one or other may predominate. Their course is entirely different from that of the neuropathies described above. Thus, they develop extremely slowly over many years and are directly related to the duration of diabetes; they are very common but, as with other diabetic complications, not all patients develop them. They are related to the presence of these other complications (i.e. retinopathy and nephropathy) although even severe neuropathy can occur in isolation. Once present, these neuropathies never remit or recover. Whether there are any effective methods for altering their course will be discussed.
There are three problems in assessing the progression of diabetic neuropathy: the first is that different nerve fibres are affected at different rates; the second, that the changes take place over many years and there are few studies which make observations over more than 2 years, with only rare reports between 5 and 10 years. Finally, methods of measurement have relatively high coefficients of variation making it impossible to detect minor changes accurately.

\section{Nerve fibre types}

Small nerve fibres, myelinated and unmyelinated, are affected first in diabetic neuropathy [27] and although some authorities disagree [28] most of the evidence suggests this to be the case.

R.D.Lawrence made this observation as a result of purely clinical observations: "It appears that the first attack is on the non-medullated nerve fibres and the early symptomatology due to their degeneration [29]".

The smallest nerve fibres transmit the modalities of pain and temperature sensation and also include autonomic transmission as well. Thus, one finds patients with diminished thermal sensation together with sympathetic nerve defects reflected in a high peripheral blood flow [3, 30] while large fibre modalities (vibration, perception, light touch and joint position sense) remain normal. This pattern of selective fibre damage can occur in both lower and upper limbs. It can be very interesting to witness some patients with obvious neuropathy associated with foot ulcerations whose light touch sensation remains absolutely normal. We have also noted (unpublished observations) a small group of young patients who are affected by severe autonomic symptoms with gross loss of peripheral temperature sensation, vascular medial calcification (i. e. due to sympathetic denervation, see below) and foot ulceration whose other sensory modalities remain normal (Table 2).

Later progression of the disease comes to affect all fibre types but the selective loss described can be very persistent. One of the only studies conducted over 10 years (in renal transplant patients) highlights the problems encountered in studying the evolution of neuropathy because of differential rates of change: thus it was observed that motor nerve conduction, though impaired, did not change during the 10 years yet muscle action potentials continued to deteriorate [31].

\section{Serial measurements of nerve function}

Nerve function declines with age. It is therefore always difficult to define the point at which this decline is faster than expected, the result of the accelerated decline lead-

Table 2. Features of small fibre neuropathies

\begin{tabular}{ll}
\hline Clinical & Pathophysiological \\
\hline Autonomic symptoms & Autonomic dysfunction \\
Charcot joints & High blood flow \\
Foot ulcers & Vascular calcification \\
Feet not numb & Loss of thermal sense \\
& Normal vibration and light touch \\
\hline
\end{tabular}


ing to diabetic neuropathy. Most studies of 2 years' duration report either no observable changes or a very small deterioration which is usually within the limits of the errors of measurement [32-35]. For this reason the unlikely observation made in some studies that conduction in different nerves deteriorates at different rates may be spurious and misleading. Observations during longer periods lead to differing conclusions with deterioration of motor nerve conduction velocity apparent in one study during 5 years [36], whereas in another there was no deterioration during 10 years [31].

Autonomic function also deteriorates with increasing age and with duration of diabetes $[37,38]$. Heart rate variability during deep breathing (six breaths per min) provides a sensitive and reasonably reproducible measure of cardiac vagal innervation and there are extensive reports on the use of this test (lower limit of normal under 60 years of age is 15 beats per min). It is commonly abnormal in diabetic patients with an overall prevalence as high as $21.5 \%$ [37]. A decline of approximately one beat per min per 3 years occurs in normal subjects and is approximately three times faster in diabetic patients studied over 10 years although the rates of deterioration vary considerably [39]. Observations during only 2 years show either no change or only a very small deterioration of heart rate variability and other tests of autonomic function [33, $40-42$ ]. It is surprising how rarely symptoms of autonomic neuropathy develop despite the very common decline of autonomic function to clearly abnormal levels.

\section{Can the course of neuropathy be altered?}

Many agents have been used to try and ameliorate the course of diabetic neuropathy [7]. Most have been tried for only short periods of time, and even studies over 2 years may not be long enough, given the slow progression of the disease and difficulties of measurement. The substances which have been used include aldose reductase inhibitors, gangliosides, gamma linolenic acid (evening primrose oil), myo-inositol, vitamins, prostaglandins, aspirin and dipyridamole. None is of proven clinical value. Studies of aldose reductase inhibitors especially in animals, have been promising [7] but trials of early neuropathy for a sufficiently long period of time are still needed.

The value of tight diabetic control is extensively documented, although many of the conflicting results are the result both of the brevity of the studies and the difficulties of maintaining 'normoglycaemia' for several years. Better techniques of achieving this goal have, however, made such studies possible, using either multiple insulin injections, continuous subcutaneous insulin infusions or more recently, pancreatic transplantation.

Early improvements of nerve function, both somatic and autonomic, have frequently been described during the early weeks and months after diabetic control has been improved [43]. They are likely to represent physiological changes and not any alteration in the development of neuropathy itself. Otherwise, studies of tight control over 2 years even by pancreatic transplantation [44] have shown either no benefit or at best an arrest of the small amount of decline which is detectable during that period $[32-35,40]$.

The most recent observations from Minneapolis following pancreatic transplantation in 61 patients (35 of whom were non-uraemic receiving a pancreatic graft only) and reviewed for up to three and a half years are both important and encouraging [41]. Although autonomic function seems relatively resistant to improved control, even over this long period, there are clear trends towards improved motor and sensory function compared with their tendency to deteriorate in those on conventional treatment. These results are the most encouraging so far and are probably amongst the first to show actual improvement.

\section{Natural history of symptomatic autonomic neuropathy}

Clinical features of autonomic neuropathy are rare which is surprising and unexplained considering the high prevalence of diminished autonomic function [37]. Only impotence is common and that is difficult to assess. Autonomic neuropathy causes gastro-intestinal problems (diarrhoea and, very rarely, vomiting from gastroparesis); gustatory sweating with the characteristic distribution of sweating over the face, scalp and neck in response to chewing tasty foodstuffs, especially cheese; cardiovascular disorders notably postural hypotension or a persistent tachycardia sometimes with a fixed heart rate, while peripheral sympathetic denervation causes the high foot blood flow now known to be characteristic of diabetic neuropathy and probably underlies many of the problems of the diabetic foot. Rarely, does bladder dysfunction develop leading to poor micturition and eventually urinary retention and recurrent urinary tract infections. There are many other defects but they do not cause symptoms and loss of warning of hypoglycaemia is not due to autonomic neuropathy.

Descriptions of the evolution of autonomic symptoms are rare indeed. We have recently reviewed such patients during 10 to 15 years [39]. Diarrhoea and vomiting (very rare) are inexplicably intermittent, and postural hypotension variable in severity though generally persistent (Fig.2). These features, and the very characteristic gustatory sweating, rarely remit, they generally persist over many years, but hardly ever progress to the point of disablement. Cases of intractable and disabling vomiting, diarrhoea or postural hypotension are thus rarely seen.

Mortality of autonomic neuropathy has been reported as being between 40 and $60 \%$ after 5 years [ 45,46$]$. Our experience is different: thus mortality for patients with diminished heart rate variability alone (without symptoms) is the same as for control subjects and $90 \%$ are still alive after 10 years [39]. The prognosis is not as good for those with symptomatic autonomic neuropathy $(73 \%$ alive after 10 years) with the greatest risk to those with postural hypotension as others have shown. A very small number of deaths are unexplained and thought to be due to respiratory arrests resulting from autonomic neuropathy: although proof for this is lacking, non-fatal respiratory arrests in these patients have been described [47, 


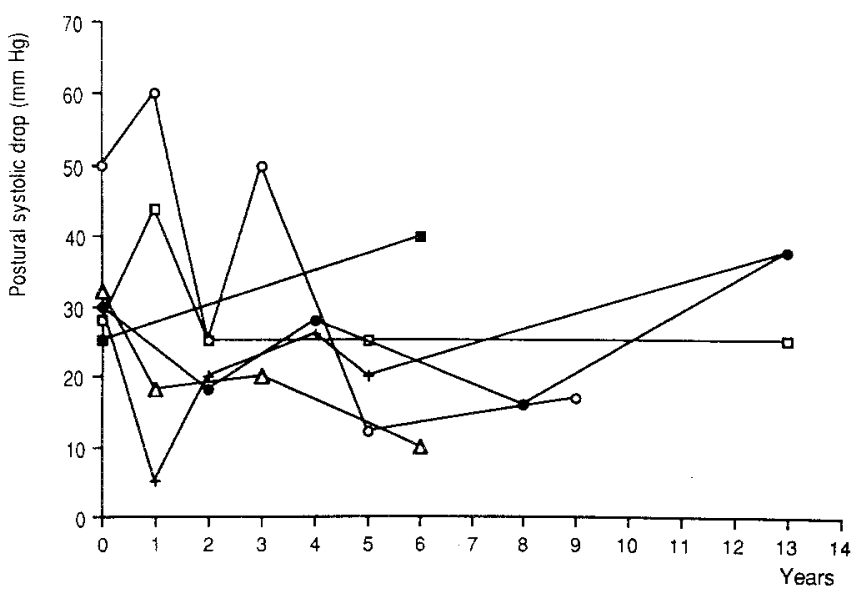

Fig. 2. Serial measurements of postural drop in systolic pressure in six patients who presented initially with a postural drop of $>30 \mathrm{~mm} \mathrm{Hg}[39]$

48]. Whether cardiac arrhythmias are responsible is unknown, although autonomic neuropathy can cause prolongation of the QT interval [49] which in other instances may predispose to ventricular fibrillation. Otherwise, deaths in autonomic neuropathy patients are due predominantly to renal failure and cardiac disease. Successful pancreatic transplantation was recently reported to show improved survival of patients with abnormal autonomic function [46].

Symmetrical sensory and autonomic neuropathy is a classic long-term diabetic complication, which progresses at a slow, though very variable, rate and never recovers. The involvement of different nerve fibre types progressing at different rates needs to be taken into account in planning studies. Trials of most therapeutic agents have not convincingly altered the course of neuropathy. However, the prolonged 'normoglycaemia' which follows pancreatic transplantation appears to conserve neurological function, and perhaps even improve it, providing the best evidence so far for the benefits of good control.

Many of these observations have of course already been made by observant physicians. Professor John Malins once wrote:

"Generally the prognosis for symptoms of neuropathy is good, but for sensory loss and reflexes uncertain and usually incomplete ...... the prognosis for autonomic manifestations is poor although the disability is often surprisingly slight [50]".

\section{Physiological observations}

\section{Blood flow in neuropathy}

"Only by experimenting ..... can we build up the majestic file of factual information from which our understanding of the natural world will grow". (Sir Peter Medawar in 'Advice to a young scientist' [51]).

Peripheral blood flow in diabetic neuropathy is grossly abnormal [3]. The very high skin and bone blood flow associated with arteriovenous shunting is well described: this has been shown by different measurement techniques, and the shunting demonstrated both by passage of labelled microspheres and by finding a high venous $\mathrm{p}_{2}$.

Sympathetic denervation of blood vessels is the cause of the high blood flow and opening of the arterio-venous anastomoses, although metabolic factors (e.g. hyperglycaemia) also raises peripheral blood flow, and there may also be intrinsic vascular abnormalities [52]. Sympathetic denervation seems to be related to a vascular medial degeneration, leading to increased vascular rigidity and calcification which are characteristic of diabetic neuropathy, even in young patients in their third and fourth decades [53].

The high peripheral blood flow is almost certainly responsible for a variety of clinical abnormalities, notably neuropathic oedema which is sometimes severe and intractable; and probably osteopoenia which follows the high blood flow and might be responsible in fact for bony fragility as a prelude to the Charcot joint. As a result of these observations Edmonds made the remarkable observation that the sympathomimetic agent ephedrine reduces neuropathic oedema very effectively, as well as altering blood flow patterns seen by ultrasonography [3].

\section{Vascular reactivity}

Recent observations on blood flow reactivity may throw further light on distinguishing neuropathies which recover from those which progress.

Sympathetic stimulation. Coughing normally causes sympathetic stimulation and cutaneous vasoconstriction [12]. Patients with classic sensory neuropathy associated with foot ulcers do not show vasoconstriction in response to this stimulus: this is entirely distinct from the response in patients with distal painful neuropathy in whom the vasoconstriction response is often entirely normal (Fig.3). More recently Young and colleagues have demonstrated the preservation of noradrenaline levels in these patients compared with its loss in conventional sensory neuropathy patients [54]. Further, Archer, while conducting these blood flow studies, observed the reduction in pain which occurred during periods of reduced blood flow [12]. This accords with observations frequently made by these patients that cooling the feet alleviates the pain; there may be useful therapeutic lessons to be learnt from these observations, although some attempts to reduce pain using ephedrine have not been successful.

These observations provide evidence for physiological distinctions in the neuropathies which recover (painful neuropathy) from those which progress (sensory and autonomic neuropathy) lending more weight to the idea that they are entirely distinct conditions.

Heat stimulus. Applications of heat to the skin normally causes a vasodilatation. Tooke has previously shown that the peak response in patients with long-standing diabetes is blunted, suggesting that the capillary structure is altered, i.e. microvascular sclerosis [52]. Using laser Doppler technology, we have recently demonstrated an 

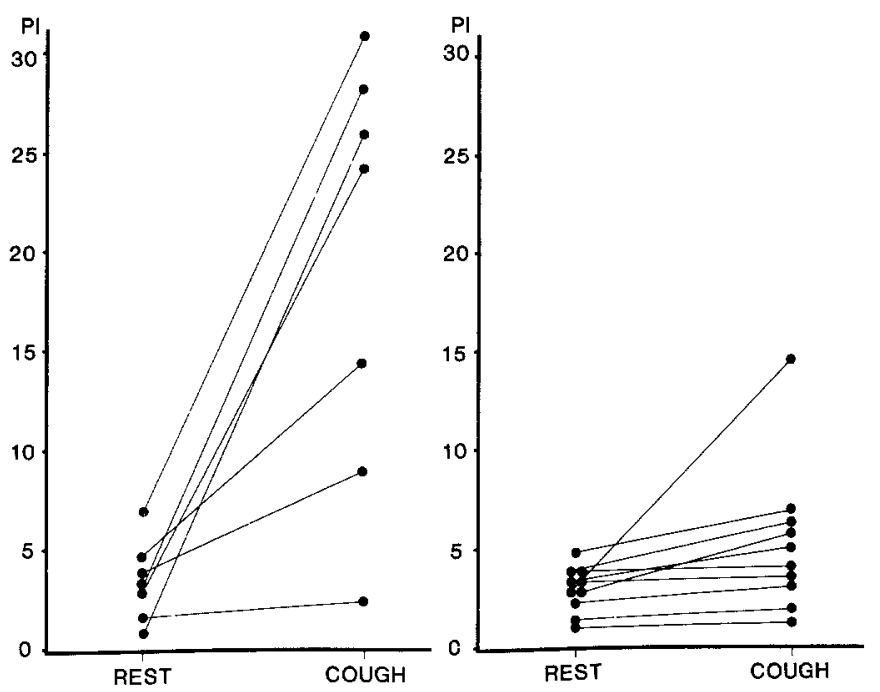

Fig. 3. Pulsatility index (PI) in diabetic patients with either painful (left panel) or conventional sensory (right panel) neuropathy. The increase in pulsatility index on sympathetic stimulation following coughing indicates vasoconstriction which occurs in the painful but not the sensory neuropathy patients [12]

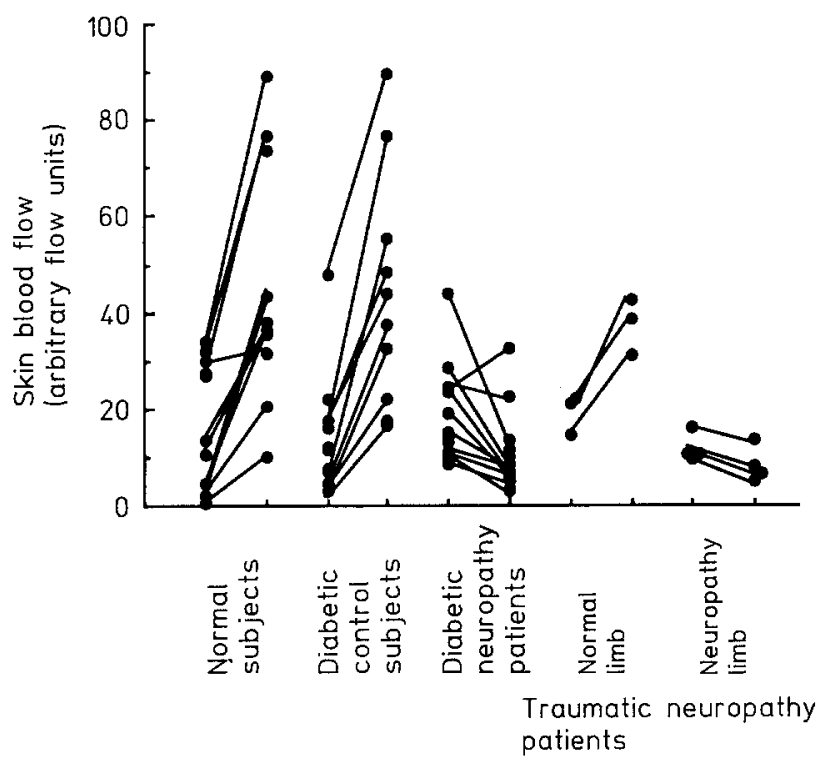

Fig.4. Foot blood flow responses to heating, assessed by laser Doppler. Paradoxical vasoconstriction occurs in diabetic neuropathy patients $(p<0.05)$, and also in the neuropathic (but not the non-neuropathic) limb of non-diabetic patients with unilateral "traumatic" neuropathy. Normal subjects $p<0.01$, diabetic control subjects $p<0.05$ for increase in blood flow response. (Edmonds and Stevens, unpublished data)

astonishing paradoxical response of the toe capillaries to heat, and observed that in patients with severe sensory neuropathy, vasoconstriction occurs instead of the expected vasodilatation [55] (Fig.4). This abnormal response occurred only at the toe which is rich in arteriovenous anastomoses, and not on the dorsum of the foot which is not. The explanation for these observations is not entirely clear, but others have shown similar paradoxical responses in situations where the normal sympathetic vas- constrictor tone is reduced in a hot environment, allowing local axon reflexes to alter skin blood flow independently in response to changes in local environment [55].

Blood flow studies performed by Edmonds and Stevens (unpublished) on non-diabetic patients with unilateral traumatic neuropathies have led to the conclusions that even these non-diabetic neuropathies result in the same paradoxical vasoconstrictor response to heat, while the responses in the normal unaffected limb were normal and vasodilatory in character (Fig. 4). Thus, it seems that neuropathy per se is responsible for the phenomenon, and that it is not due to diabetic microvascular disease which was obviously not a feature of those with traumatic neuropathies.

Whether these abnormal microvascular responses are in any way responsible for the disorders of the diabetic foot remains to be determined.

\section{Nerve structure}

Studies of the nerve structure by examination of sural nerve biopsy specimens have also demonstrated distinctions between reversible (painful) neuropathies and established sensory and autonomic neuropathies. Thus, the myelinated nerve fibre loss can be less severe in those with acute painful neuropathy, and regenerating nerve fibres less prominent [56]. Further, Thomas and Llewelyn have studied two sural nerve biopsies taken 9 years apart from one of our male patients (personal communication): at the first biopsy in 1977 the patient had exceptionally severe painful neuropathy; 9 years later, long after the pain had subsided, a second biopsy was taken at the time of amputation following development of peripheral vascular disease and sepsis. While loss of myelinated fibres progressed, regenerating fibres actually increased both in actual numbers and proportion (Table 3). This increase in regenerating nerve fibres occurred when the pain had since resolved. Our observations suggest an absence of any relationship with regenerating nerve fibres with pain, and show that they are usually most prominent in those with the greatest myelinated fibre loss, which is not necessarily in those with painful neuropathy.

\section{Immunological mechanisms and autonomic neuropathy}

There is, at present, no explanation why symptomatic autonomic neuropathy is so uncommon while impairment of autonomic function is so widespread. We have recently postulated that an additional immunologically-mediated attack on small nerve fibres may contribute to the defects responsible for symptomatic autonomic neuropathy.

In 1984 we described the features of a possible new syndrome, namely the association of iritis with severe symptomatic diabetic autonomic neuropathy. Fourteen of 47 Type 1 diabetic patients under 40 years of age were found to have been treated with topical steroids by ophthalmologists for iritis up to 5 years previously. All of these patients had exceptionally severe symptomatic autonomic neuropathy often associated with Charcot joints [57]. 
Table 3. Sural nerve biopsies ${ }^{a}$ in painful neuropathy

\begin{tabular}{lrrr}
\hline Fibre types & \multicolumn{1}{c}{1977} & \multicolumn{1}{c}{1986} & \multicolumn{1}{c}{ Normal } \\
\hline Myelinated $\left(\right.$ per $\left.\mathrm{mm}^{2}\right)$ & 6,014 & 2,597 & $7,500-10,000$ \\
Unmyelinated $\left(\right.$ per $\left.\mathrm{mm}^{2}\right)$ & 19,846 & 14,320 & $30,000-40,000$ \\
Regenerating & 12 & 159 & \\
myelinated (per $\left.\mathrm{mm}^{2}\right)$ & & & \\
\% regenerating & 0.2 & 6.1 & \\
\hline
\end{tabular}

a These biopsies were taken from a diabetic patient who in 1977 had a particularly severe painful neuropathy affecting legs and perineum: this resolved completely during the ensuing years. The second (1986) biopsy was taken at the time of amputation for severe sepsis and peripheral vascular disease. (By kind permission of Dr. G.Llewelyn and Prof. P.K. Thomas)

Table 4. Diabetic neuropathies: recovery vs progression

\begin{tabular}{lll}
\hline & $\begin{array}{l}\text { Painful/mono- } \\
\text { neuropathies }\end{array}$ & $\begin{array}{l}\text { Sensory, } \\
\text { autonomic }\end{array}$ \\
\hline Onset & Acute & Gradual \\
Duration of diabetes & Any & Long standing \\
Other complications & None & Often \\
Sex & $\mathrm{M}>\mathrm{F}$ & $\mathrm{M}=\mathrm{F}$ \\
Diabetes type & Type 2 Type 1 & Type 1+ Type 2 \\
Evolution & Recovery & Progression \\
\hline
\end{tabular}

Similar observations have been made by two other centres since our original description. Rothova et al. [58] found that $16(12.5 \%)$ of 128 patients with idiopathic anterior uveitis had diabetes compared with $1.9 \%$ amongst patients with an established ocular diagnosis. Ten of the 16 patients had autonomic neuropathy [58].

Recently, Barzilay et al. [59] have reported an increased propensity of subjects with HLA-DR 3/4 for autonomic neuropathy and have suggested that autonomic neuropathy may develop on an autoimmune basis.

The observation of inflammatory cellular infiltrations of lymphocytes, macrophages and occasional plasma cells in autonomic ganglia and in relation to autonomic nerve bundles in post-mortem specimens from five patients with severe autonomic neuropathy led to the suggestion of the possibility of an immunological basis for this disorder [60]. More recently, in conjunction with Prof. P.K.Thomas, we have examined sural nerve biopsies in eight patients but so far have not discovered cellular infiltrates or immunoglobulin deposition. Vlassara et al. [61] have suggested that macrophages might recognise and interact with glycosylated myelin products, thus contributing to segmental demyelination.

We have, more recently, examined our severely symptomatic autonomic neuropathy patients both with and without iritis for the development of both cellular and humoral features of immunological phenomena. Circulating immune complexes $(\mathrm{Clq})$ were on average raised in these patients, as were C $3 \mathrm{~d}$ levels suggesting complement activation [62]. Activated T-lymphocytes, which may play a role in some forms of allergic neuritis, were also elevated [63]. The presence of anti-sympathetic ganglia antibodies in relation to postural hypotension has recently been reported from the Joslin Clinic [64]; these antibodies may occur more commonly than expected in a diabetic popula- tion, though not necessarily in association with autonomic neuropathy [65].

The mechanisms of the immunological damage remain speculative. The hypothesis is based on the idea that insulin antibodies might cross-react with nerve growth factor which has some similarities with the structure of insulin and is concerned with the development and perhaps maintenance of sympathetic nerves. Nerve growth factor also accumulates in denervated irises and this could provide the link between autonomic neuropathy and the development of iritis. The question of the possible relationship between immunological mechanisms and autonomic neuropathy needs further investigations; the arguments so far have nevertheless been sufficiently powerful to lead to an attempt at immunosuppressive treatment in two cases of severe autonomic neuropathy with limited but apparently positive results [66].

\section{Conclusions (Table 4)}

Diabetic neuropathies form a group of diverse conditions: it is notable that there are very marked distinctions between those which recover (acute painful neuropathies, radiculopathies, mononeuropathies) and those which progress (sensory and autonomic neuropathy). There are many clinical, structural and physiological differences between these groups. The idea that immunological mechanisms may precipitate severe symptomatic autonomic neuropathy is presented, although the explanations for these striking differences are otherwise obscure. Their identification however, paves the way for new clinical research. The great physician Sir Thomas Lewis once wrote: "There is indeed a fertile science that deals primarily with patients and this must be encouraged to a more vigorous growth" [67].

Acknowledgements. Bernard Naunyn who made such a substantial contribution to the study of diabetes, and in whose Strasbourg laboratories Von Mering and Minkowski made their observations on pancreatectomy, wrote in his autobiography: "The demon that urges you in research and nags at you and can only be pacified by relentless work was not always active in Minkowski and needed to be encouraged" [68]. I have in mind countless research fellows and assistants much of whose work I have described in this review and who have been so responsive to encouragement, especially Dr. Alan Archer, Dr, Michael Flynn, Dr. Stephen Gilbey, Dr. Ana Grenfell, Dr. Roland Guy, Dr. Jonathan Mackay, Dr. Michael Page, Dr. Michael Sampson and Dr. Martin Stevens. The contributions of my colleague Dr. Michael Edmonds to this field have been especially outstanding, and Dr. Paul Drury gives constant and invaluable support. I would like to salute in particular my colleague, Dr. David Pyke, whose relentless energy and major clinical contributions in diabetes research have been such an inspiration; and my former chief Prof. John Malins who introduced me to diabetes, and whose great clinical skill, keen observations and kindness have had such an important influence. I am most honoured to have been the recipient of the Castelli Pedroli prize. I am extremely grateful too for long-standing and substantial support from the British Diabetic Association.

\section{References}

1. Ryle JA (1936) The natural history of disease. Oxford University Press, London, pp 1-23

2. Dyck PJ, Thomas PK, Asbury AK, Winegrad AI, Porte D (eds) (1987) Diabetic neuropathy. Saunders, Philadelphia 
3. Edmonds ME, Watkins PJ (1988) Clinical presentations of diabetic autonomic failure. In: Bannister $\mathrm{R}$ (ed) Autonomic failure. Medical Publications, Oxford, pp 632-653

4. Ewing DJ (1988) Recent advances in the non-invasive investigation of diabetic autonomic neuropathy. In: Bannister R (ed) Autonomic failure. Medical Publications, Oxford, pp 667-689

5. Ewing DJ, Clarke BF (1986) Autonomic neuropathy: its diagnosis and prognosis. In: Watkins PJ (ed) Long term complications of diabetes. Clinics in endocrinology and metabolism. Saunders, London, pp 855-888

6. Ewing DJ, Clarke BF (1987) Diabetic autonomic neuropathy: a clinical viewpoint. In: Dyck PJ, Thomas PK, Asbury AK, Winegrad AI, Porte D (eds) Diabetic neuropathy. Saunders, Philadelphia, pp 66-88

7. Greene DA, Lattimer SA, Sima AAF (1988) Pathogenesis and prevention of diabetic neuropathy. Diab Metab Rev 4: 201-221

8. Pfeiffer MA, Peterson H (1987) Cardiovascular autonomic neuropathy. In: Dyck PJ, Thomas PK, Asbury AK, Winegrad AI, Porte D (eds) Diabetic neuropathy. Saunders, Philadelphia, pp 122-133

9. Vinik A, Mitchell B (1988) Clinical aspects of diabetic neuropathies. Diab Metab Rev 4:223-253

10. Mackenzie J quoted by Pickles WN (1939) Epidemiology in country practice. John Wright, Bristol, p 114

11. Archer AG, Watkins PJ, Thomas PK, Sharma AK, Payan J (1983) The natural history of acute painful neuropathy in diabetes mellitus. J Neurol Neurosurg Psychiat 46:491-499

12. Archer AG, Roberts VC, Watkins PJ (1984) Blood flow patterns in painful diabetic neuropathy. Diabetologia 27: 563-567

13. Boulton AJM, Ward JD (1986) Diabetic neuropathies and pain. In: Watkins PJ (ed) Long term complications of diabetes. Clinics in endocrinology and metabolism. Saunders, London, pp 917-931

14. Ellenberg M (1974) Diabetic neuropathic cachexia. Diabetes 23: 418-423

15. Llewelyn JG, Thomas PK, Fonseca V, King RHM, Dandona P (1986) Acute painful neuropathy precipitated by strict diabetic control. Acta Neuropathol 72: 157-163

16. Ward JD (1982) The diabeticleg. Diabetologia 22: 141-147

17. Steel JM, Young RJ, Lloyd CG, Clark BF (1987) Clinically apparent eating disorders in young diabetic women: associations with painful neuropathy and other complications. Br Med J 294: 859-862

18. Boulton AJM, Armstrong WD, Scarpello JHB, Ward JD (1983) The natural history of painful diabetic neuropathy. Postgrad Med J 59: 556-559

19. Young RJ, Ewing DJ, Clark BF (1988) Chronic and remitting painful diabetic polyneuropathy. Diab Care 11:34-40

20. Bastron JA, Thomas JE (1981) Diabetic polyradiculopathy. Clinical and electromyographic findings in 105 patients. Mayo Clinic Proc 56: 725-732

21. Stewart JD (1989) Diabetic truncal neuropathy topography of the sensory deficit. Ann Neurol 25: 233-238

22. Boulton AJM, Angus E, Ayyar DR, Weiss R (1984) Diabetic thoracic polyradiculopathy presenting as abdominal swelling. $\mathrm{Br}$ Med J 289: 798-799

23. Casey EB, Harrison MJ (1972) Diabetic amyotrophy: a followup study. Br Med J 1: 656-659

24. Chokroverty S, Reyes MG, Rubino FA, Tonaki H (1977) The syndrome of diabetic amotrophy. Ann Neurol 2: 181-194

25. Coppack SW, Watkins PJ (1991) The natural history of diabetic femoral neuropathy. Quart J Med 79: 307-313

26. Leslie RDG, Ellis C (1978) Clinical course following diabetic ocular palsy. Postgrad Med J 54: 791-792

27. Guy RJC, Clark CA, Malcolm PN, Watkins PJ (1985) Evaluation of thermal and vibration sensation in diabetic neuropathy. Diabetologia 28: 131-137

28. Dyck PJ, Karnes JL, Daube J, O’Brien P, Service FJ (1985) Clinical and neuropathological criteria for the diagnosis and staging of diabetic polyneuropathy. Brain 108: 861-880

29. Lawrence RD (1965) The diabetic life. Churchill, London, p 157
30. Watkins PJ, Edmonds ME (1983) Sympathetic nerve failure in diabetes. Diabetologia 25: 73-77

31. van der Vliet JA, Navarro X, Kennedy WR, Goetz FC, Barbosa JJ, Sutherland DER, Najarian JS (1988) Long-term follow-up of polyneuropathy in diabetic kidney transplant recipients. Diabetes 37: 1247-1252

32. Dahl-Jorgensen K, Brinchmann-Hansen O, Hanssen KF et al. (1986) Effect of near normoglycaemia for two years on progression of early diabetic retinopathy, nephropathy and neuropathy: the Oslo study. Br Med J 293: 1195-1199

33. Jakobsen J, Christiansen JS, Kristoffersen I et al. (1988) Autonomic and somatosensory nerve function after 2 years of continuous subcutaneous insulin infusion in type 1 diabetes. Diabetes 37: 452-455

34. Lauritzen T, Frost-Larsen K, Larsen HW, Deckert T and the Steno Study Group (1985) Two-year experience with continuous subcutaneous insulin infusion in relation to retinopathy and neuropathy. Diabetes 34: 74-79

35. Service FJ, Rizza RA, Daube JR, O'Brien PC, Dyck PJ (1985) Near normoglycaemia improved nerve conduction and vibration sensation in diabetic neuropathy. Diabetologia $28: 722-727$

36. Bischoff A (1980) The natural course of diabetic neuropathy: a follow-up. Horm Metab Res [Suppl] 9: 98

37. O'Brien IAD, O'Hare JP, Lewin IG, Corrall RJM (1986) The prevalence of autonomic neuropathy in insulin dependent diabetes mellitus: a controlled study based on heart rate variability. Quart J Med 61: 957-967

38. Wieling W, van Brederode JFM, de Rijk LG, Borst C, Dunning AJ (1982) Reflex control of heart rate in normal subjects in relation to age: a data base for cardiac vagal neuropathy. Diabetologia 22: 163-166

39. Sampson MJ, Wilson S, Karagiannis P, Edmonds ME, Watkins PJ (1990) Progression of diabetic autonomic neuropathy over a decade in insulin dependent diabetics. Quart J Med 75:635-646

40. Fedele D, Bellavere F, Cardone C, Ferri M, Crepaldi G (1985) Improvement of cardiovascular autonomic reflexes after amelioration of metabolic control in insulin dependent diabetic subjects with severe autonomic neuropathy. Horm Metab Res 17: $410-413$

41. Kennedy WR, Navarro X, Goetz FC, Sutherland DER, Najarian JS (1990) The effects of pancreas transplantation on diabetic neuropathy. New Engl J Med 322: 1031-1037

42. St Thomas' Diabetic Study Group (1986) Failure of improved glycaemic control to reverse diabetic autonomic neuropathy. Diab Med 3: 330-334

43. Troni W, Carta O, Cantello R, Caselle MT, Rainero I (1984) Peripheral nerve function and metabolic control in diabetes mellitus. Ann Neurol 16: 178-183

44. Solders G, Gunnarsson R, Persson A, Wilczek H, Tyden C, Groth C-G (1987) Effects of combined pancreatic and renal transplantation on diabetic neuropathy: a two year follow-up study. Lancet II: 1232-1235

45. Ewing DJ, Campbell D, Clarke BF (1980) The natural history of diabetic autonomic neuropathy. Quart J Med 49: 95-100

46. Navarro X, Kennedy WR, Loewenson RB, Sutherland DER (1990) Influence of pancreas transplantation on cardiorespiratory reflexes, nerve conduction and mortality in diabetes mellitus. Diabetes 39: 802-806

47. Page MM, Watkins PJ (1978) Cardiorespiratory arrests and diabetic autonomic neuropathy. Lancet I: 14-16

48. Kageyama S, Sasoh F, Taniguchi I, Homma I, Saito H, Isogai Y (1985) Cardiorespiratory arrest in a patient with advanced diabetic autonomic neuropathy. Diab Res Clin Pract 1:243-246

49. Chambers JB, Sampson MJ, Sprigings DC, Jackson G (1990) QT prolongation in diabetic neuropathy. Diab Med 7: 105-110

50. Malins JM (1968) Clinical diabetes mellitus. Eyre and Spottiswoode, London, pp 237-238

51. Medawar P (1979) Advice to a young scientist. Harper and Row, New York, $\mathrm{p} 70$

52. Tooke JE (1989) Microcirculation and diabetes. Br Med Bull 45: 206-223 
53. Goss DE, Trafford JC, Roberts VC, Flynn MD, Edmonds ME, Watkins PJ (1989) Raised ankle/brachial pressure index in insulin treated diabetic patients. Diab Med 6:576-578

54. Tsigos C, White A, Young RJ (1990) Painless and painful diabetic polyneuropathy: discriminating differences. Diab Med: 7 [Suppl 2]: 4A (Abstract)

55. Stevens MJ, Edmonds ME, Douglas SLE, Watkins PJ (1991) The influence of neuropathy on the microvascular response to local heating in the human diabetic foot. Clin Sci 80: 249-256

56. Llewelyn JG, Gilbey SG, Thomas PK, King RHM, Muddle JR, Watkins PJ (1991) Sural nerve morphometry in diabetic autonomic and painful sensory neuropathy: a clinicopathological study. Brain 114: 867-892

57. Guy RJC, Richards F, Edmonds ME, Watkins PJ (1984) Diabetic autonomic neuropathy and iritis: an association suggesting an immunological cause. Br Med J 289: 343-345

58. Rothova A, Meenken C, Michels RPJ, Kijlstra A (1988) Uveitis and diabetes mellitus. Am J Ophthalmol 109: 17-20

59. Barzilay J, Derby L, Rand LI, Pfeifer MA, Krolewski AS (1989) Determinants of autonomic neuropathy in insulin dependent diabetes. Diabetes 38: 121 (Abstract)

60. Duchen LW, Anjorin A, Watkins PJ, Mackay JD (1980) Pathology of autonomic neuropathy in diabetes mellitus. Ann Int Med 92: 301-305

61. Vlassara H, Brownlee M, Cerami A (1985) Recognition and uptake of human diabetic peripheral nerve myelin by macrophages. Diabetes 34: 553-557
62. Gilbey SG, Guy RJC, Jones H, Vergani D, Watkins PJ (1986) Diabetes and autonomic neuropathy: an immunological association? Diab Med 3: 241-245

63. Gilbey SG, Hussain MJ, Watkins PJ, Vergani D (1988) Cellmediated immunity and symptomatic autonomic neuropathy. Diab Med 5: 845-848

64. Rabinowe SL, Brown FM, Watts M, Kadrofgke MM, Vinik AI (1989) Anti-sympathetic ganglia antibodies and postural pressure in IDDM subjects of varying duration and patients at high risk of developing IDDM. Diab Care 12: 1-6

65. Sundkvist G, Lind P, Bergstrom B, Lilja B, Rabinowe SL (1991) Autonomic nerve antibodies and autonomic nerve function in Type 1 and Type 2 diabetic patients. J Int Med 229: 505-510

66. Rabinowe SL (1990) Immunology of diabetic and polyglandular neuropathy. Diab Metab Rev 6: 169-188

67. Lewis T (1930) Research in medicine: its position and its needs. Br Med J I: 479-483

68. Naunyn B (1925) Translated by: I. Watkins. From: Erinnerungen, Gedanken und Meinungen. Bergmann, München

Dr. P.J. Watkins

Diabetic Department

King's College Hospital

Denmark Hill

London SE5 9RS

UK 